\title{
Educación Superior y COVID-19: A propósito de Derechos y Garantías Fundamentales
}

\section{Higher Education and COVID-19: Regarding Rights and Fundamental Guarantees}

\author{
Eva Andrés Aucejo \\ Catedrática de Derecho Financiero y Tributario. \\ Directora de la Revista de Educación y Derecho. \\ Departamento de Derecho Administrativo, Derecho Procesal y Derecho Financiero \\ y Tributario. \\ Universidad de Barcelona, España. \\ E-mail: eandres@ub.edu
}

\section{Jorge Castellanos Claramunt}

Profesor Ayudante Doctor de Derecho Constitucional.

Coordinador General del Peer Review de la Revista de Educación y Derecho.

Departamento de Derecho Constitucional, Ciencia Política y de la Administración

Universidad de Valencia, España.

E-mail: jorge.castellanos@uv.es

\section{Ricard Martínez Martínez}

Profesor Contratado Doctor de Derecho Constitucional.

Director de la Cátedra de privacidad y Transformación Digital Microsoft-Universitat de Valencia.

Departamento de Derecho Constitucional, Ciencia Política y de la Administración Universidad de Valencia, España.

E-mail: ricard.martinez@uv.es 
Sean éstas nuestras primeras frases de felicitación a los autores de la sección monográfica del número 22 de la Revista de Educación y Derecho que hoy presentamos bajo el sugerente título: “COVID-19: Docencia online y protección de Derechos y Garantías Fundamentales". Título, sin lugar a dudas ambicioso en cuanto a contenidos, planteamientos, diques y retos; aristas todas ellas, que a nuestro modesto juicio se han alcanzado con un meritorio y destacado éxito.

Cuando desde la redacción de la Revista, el Doctor Castellanos Claramunt (Coordinador General del Comité de Peer Review de la misma) me propusiera facilitar la coordinación de un número dedicado a la problemática generada por la pandemia COVID-19 en Educación Superior, inmediatamente arbitramos los caminos que nos condujeran al fin... Algo, consideramos, había que aportar desde las Ciencias Jurídicas y Políticas. Su oportunidad alentaba nuestra prioridad.

Una preocupación, empero, latió desde el inicio en el Consejo Editorial de la Revista. Lejos de enfoques divulgativos, reiterativos y carentes de contenidos sustanciales, nos movió el reto de arbitrar un monográfico de naturaleza científica, serio, al uso de las revistas de corte jurídico científico que, como la presente, han sido indexadas en la Web of Science (JCR, entre otras plataformas y bases de datos). Monográfico analizado, por otra parte, desde los requiebros provenientes de las disciplinas de las Ciencias Jurídicas y Políticas (que no son pocos, ni fáciles de abordar).

Todo ello, siempre con el norte puesto en coronar una temática sustancial de primerísimo orden: la limitación de derechos y las libertades fundamentales ante la situación que el COVID-19 en materia de Educación Superior, así como los retos que este proceso nos plantea a las Universidades.

De ahí, la oportunidad de editar el presente número en el presente medio, así como la necesidad de contar con expertas plumas que lo alumbraran. En particular, destacados juristas impregnados por tintes constitucionalistas, de Ciencias Políticas e Historia Contemporánea. A saber: el Doctor Ricard Martínez, Director de la Cátedra de privacidad y transformación digital Microsoft y profesor de la Universidad de Valencia; David Sanz Esteban, Director en materia de Privacidad de la Universidad de Valladolid; la Doctora Mónica Arenas Ramiro, experta en garantías del Comité Europeo de Derechos Sociales y 
en Derechos fundamentales y libertades públicas (Doctora y profesora de la Universidad de Alcalá de Henares) y también el Doctor Max Turull, Secretario General del Instituto de Ciencias de la Educación y profesor de la Universidad de Barcelona.

La mayor parte de los expertos mencionados forman parte del grupo de trabajo creado a tal efecto por la Conferencia de Rectores de las Universidades Españolas integrado por los delegados de protección de datos y profesores, Mónica Arenas y Ricard Martínez, y el delegado de protección de datos de la Universitat Jaume I José Gumbau, a quiénes desde la Revista agradecemos sus contribuciones.

En términos generales, podríamos tildar de día "D” para el entorno internacional el 11 de marzo del año 2020, fecha en que la Organización Mundial de la Salud proclamó la Declaración de pandemia internacional provocada por expansión del virus SARS-Cov-2; y para el ámbito nacional, de 14 de marzo de 2020, data el Real Decreto aprobado por el Estado Español (Real Decreto 463/2020, de 14 de marzo), por cuyo artículo 9 se declara el estado de alarma para la gestión de la situación de crisis sanitarita ocasionada por la pandemia COVID-19 (BOE, n. 67 de 14 de marzo).

A partir de dichas fechas, se provoca un escenario de imbricación y subordinación al entorno que representa la pandemia mundial COVID- 19, donde las legislaciones nacionales se ven obligadas a adoptar una serie de drásticas y restrictivas medidas en pro de contener la situación de emergencia sanitaria de salud pública. El Estado Español no sería una excepción al respecto.

Desde la misma entrada en vigor del citado Real Decreto del Estado Español acaecen pues limitaciones en derechos y libertades fundamentales de primer orden, como nos alumbra de forma extraordinaria el Sanz Esteban de la Universidad de Valladolid. A saber: "la limitación de la libertad de circulación como medio fundamental para evitar los contactos directos entre ciudadanos y, por ende, la propagación de la enfermedad". O también “medidas específicas de contención en el ámbito educativo y de la formación. El artículo 9 del Real Decreto 463/2020 ordenó la suspensión de la actividad educativa presencial a todos los niveles, incluyendo la enseñanza universitaria, toda vez que se recomendaba acudir a las modalidades de docencia a distancia y "on line" siempre que esto resultara posible" y que él refiere a la situación del personal docente e investigador. Sanz Esteban ha tenido 
ocasión de analizar también con detalle otros flancos de vital importancia como las dificultades de aplicación de la Ley de prevención de riesgos laborales en el teletrabajo (recuérdese que según el artículo 13.4 del Estatuto, los trabajadores a distancia tienen derecho a una adecuada protección en materia de seguridad y salud, resultando de aplicación en todo momento lo establecido en la Ley 31/1995, de 8 de noviembre, de Prevención de Riesgos Laborales y su normativa de desarrollo); el Derecho a la intimidad en los dispositivos; el Derecho a la desconexión digital, etc.; prestando especial atención a las medidas de seguridad aplicables en las distintas modalidades de conexión en el teletrabajo. En definitiva, como su propio autor recoge: su trabajo recorre los distintos escenarios modificados por la docencia online y las implicaciones que ha tenido para las instituciones universitarias y su profesorado.

Por otra parte, la doctora Mónica Arenas en su brillante artículo titulado Cámaras e imágenes personales en el proceso de aprendizaje universitario, deja patente La clamorosa carencia de legislación adecuada a la docencia y a los exámenes online, más allá de la dispersa normativa académica en manos de las Comunidades autónomas y de las Universidades. Ello plantea -a su juicio- un escenario de incertidumbre significativo que ha causado problemas indescriptibles en un contexto muy difícil.

Las Universidades se enfrentan no sólo a un uso indebido de las imágenes que se puedan captar durante el desarrollo de las clases, sino a graves riesgos de fraude en los exámenes físicos y virtuales mediante el uso de sofisticados medios electrónicos. Es necesario que las Autoridades de protección de datos nacionales sean capaces tanto de entender la naturaleza y fines de los tratamientos en el mundo universitario, como los riesgos asociados al fraude académico y la necesidad de dotar a la comunidad universitaria de pautas concretas a seguir. En esta materia, los pronunciamientos basados en meras teorías no sirven, se requieren pautas claras.

En este proceso de transición a una educación online -dice también su autora- se hace imprescindible respetar la normativa de protección de datos y, como también veremos, la relacionada concretamente con el derecho a la propia imagen e incluso con el derecho a la propiedad intelectual. 
La Doctora Arenas analiza de una manera muy extensa el paso a un aprendizaje virtual, enfocando la cuestión en el uso de datos personales, como es el caso de imágenes personales o la voz de los implicados. Como ella misma advierte con su finura jurídica, Sin perjuicio de la protección otorgada a las imágenes personales por parte del derecho fundamental a la propia imagen, el tratamiento de las imágenes captadas por unas videocámaras o cámaras web, siempre que permita identificar a su titular de forma directa o indirectamente, deberá verse sometido a la normativa de protección de datos personales, esto es, al Reglamento (UE) 2016/679 General de Protección de Datos (RGPD) y a la LO 3/2018 de Protección de Datos Personales y Garantía de los Derechos Digitales ( $L O P D G D D)$. Por lo que concluye afirmando que "El estudio del impacto normativo del RGPD y de la LOPDGDD en este proceso exige definir modalidades de docencia y de evaluación, así como el contexto o canal en el que se realizan. La Universidad española ha debido, y debe, enfrentarse a la necesidad de definir escenarios con las metodologías docentes y los tipos de evaluación que podrían ser realizados por las Universidades en un modelo no presencial, así como la identificación de los canales por los que se podrían llevar a cabo, que básicamente son las aulas o plataformas virtuales, los sistemas de videoconferencia y los entornos de trabajo en cloud".

Argumentos que adereza con declaraciones de la propia Agencia Española de Protección de datos quién sostiene que dicho derecho a la protección fundamental de datos no es absoluto y debe analizarse con perspectiva, de forma sistemática, en el contexto social en el que se aplica y ejerce, y en equilibrio con el resto de derechos fundamentales, ampliando el círculo de análisis incluso al espacio de vida privada y familiar tutelado por el artículo 18.1 de la Constitución Española y la Ley Orgánica 1/1982, de protección civil del derecho al honor, a la intimidad personal y familiar y a la propia imagen.

En definitiva, desde este artículo se analizan las necesidades que surgen en el nuevo entorno respecto del uso de la información personal, ofreciendo recomendaciones para garantizar su uso seguro en un entorno virtual de aprendizaje.

Finalmente, en este prolijo campo de protección de datos se adentra el rigurosísimo brillante trabajo del profesor Ricard Martínez, cuya lectura recomendamos fervientemente, titulado "Tecnología de verificación de identidad y control en exámenes 
online". Tal y como afirma este autor: Las tecnologías de reconocimiento facial para la verificación de identidad y de control del acceso al espacio virtual para el desarrollo de exámenes inciden muy directamente sobre los derechos del estudiante. Su implementación y uso, implica un tratamiento de datos biométricos particularmente exigido en términos de cumplimiento normativo por el Reglamento General de Protección de Datos. En ambos casos, es necesario asegurar el debido equilibrio entre los derechos del estudiante y la garantía del derecho de la institución universitaria de articular procesos de verificación de los conocimientos que eviten el fraude.

Ello afecta de lleno a una materia delicada e importante: la evaluación y el seguimiento de los estudiantes en un entorno completamente online.

Tras la proclamación del estado de alarma y las restricciones vistas, la Universidad española debió enfrentarse el desarrollo del conjunto de sus exámenes del segundo cuatrimestre así como de segundas convocatorias, desde la carencia de cualquier base jurídica normativa expresa. El grupo de trabajo creado a tal efecto por la Conferencia de Rectores de las Universidades Españolas integrado por los delegados de protección de datos y profesores Mónica Arenas y Ricard Martínez, y el delegado de protección de datos de la Universitat Jaume I José Gumbau, a quienes aludíamos al inicio de esta presentación, alumbró un conjunto de estrategias ordenadas a conciliar la garantía de los derechos de los estudiantes con la práctica de la actividad examinadora.

La conclusión principal, en modo resumido, consistió en optar por trasladar las dinámicas propias del mundo físico al mundo virtual entendiendo que existía un tratamiento de datos legítimo, incluida la propia imagen del estudiante, en aquellos exámenes que, de acuerdo con la normativa académica y la normativa general, exigían desplegar funciones de verificación y control de la identidad del estudiante así como mantener registros o grabaciones que garantizasen el derecho del propio estudiante a la revisión de los exámenes.

Ello, acompañado de un conjunto de recomendaciones específicas en torno a la información previa que recibió el estudiante, la configuración del espacio de captación de imágenes, deberes y obligaciones en materia de secreto del profesorado y la configuración de los espacios de vida privada afectados por la captación de las imágenes. Lo que, sin embargo, no pudo resolverse por carencia de predeterminación normativa fue la utilización de las 
llamadas herramientas de proctoring. Para un desarrollo muy extenso de estos temas puede consultarse el artículo del profesor Ricard Martínez de la Universidad de Valencia, que se publica en este número 22.

En síntesis, dichas herramientas permiten desplegar dos tipos de funciones distintas. La primera consiste en el control de la identidad de los estudiantes mediante sistemas de verificación biométrica al inicio del examen y, regularmente, durante el desarrollo del mismo. La segunda permite establecer un control absoluto sobre el ordenador del estudiante que sólo puede usar la zona de trabajo autorizada. Su utilización evita la suplantación de identidad, asegurar la presencia constante del estudiante durante la prueba, y evitan el acceso a recursos tecnológicos desde el propio ordenador absteniéndose, por tanto, de prácticas o conductas fraudulentas.

Sin embargo, como bien señaló mediante informe jurídico la Agencia Española de Protección de Datos, a petición de la CRUE y confirmando las conclusiones de los delegados de protección de datos, la utilización de herramientas de identificación biométrica unívoca están sujetas a la regulación de las categorías especiales de datos en el Reglamento General de Protección de Datos y requieren de una regulación específica que autorice su uso, sean diseñadas respetando el principio de protección de datos desde el diseño y por defecto, o desarrollar una evaluación de impacto relativa a la protección de datos, posibilidades inalcanzables en una situación de urgencia. Por otra parte, no podía apelarse al consentimiento para su uso ya que en ausencia de una alternativa de libre elección para el estudiante este hubiera sido nulo. Por tanto, se renunció por completo al uso de estas técnicas.

Para concluir, el lector podrá apreciar cómo el conjunto de impactos y transformaciones en la relación jurídica subyacente a la prestación del servicio público de educación superior se ve fuertemente influenciadas en el marco de una docencia online de carácter general y obligatorio a consecuencia de la aplicación de las medidas excepcionales en la lucha contra la pandemia. De todo ello hemos aprendido un conjunto de lecciones que obligan no sólo a modular las prácticas internas de cada universidad. Aconsejan, al menos en el caso español, a proceder a una profunda revisión de la normativa que rige esta materia y a una adecuación 
a los tiempos que corren en un escenario, el del curso 2020/2021, en el que no sabemos si el recurso a este tipo de técnicas continuará siendo urgente y necesario.

Con ser todo ello importante, no lo son menos las acertadas palabras del profesor de la Universidad de Barcelona, el Dr. Max Turull también secretario general del Instituto de Ciencias de la Educación de dicha Universidad, plasmadas en la interesante y novedosa presentación del presente número. Con ellas damos cierre y entrada al mismo:

Efectivamente, las presentaciones con audio o con video, las sesiones por videoconferencia, las tutorías virtuales, las reuniones online (todas con programas cada vez más llamativos, potentes y sofisticados), los ejercicios de respuesta múltiple del campus y cualquier otro recurso, tecnológico o no, son eso: recursos. Son instrumentos para alcanzar objetivos. Antes el recurso o el instrumento principal quizá eran la clase presencial, la lección magistral presencial o la realización de ejercicios prácticos ante el profesor. Ahora los recursos o instrumentos han cambiado, pero siguen siendo recursos y en ningún caso se han convertido en objetivos en sí mismos. Por tanto conviene hacer un cierto esfuerzo por mantener la alineación constructiva. Debemos mantener perfectamente alineados los objetivos de aprendizaje - que pueden no haber variado sustancialmente con la pandemia-, la metodología y los recursos, y la evaluación. Una, o quizás dos, de las piezas han debido ser sustituidas por otras, pero deben seguir alineadas con los objetivos de aprendizaje que nos hemos planteado. 